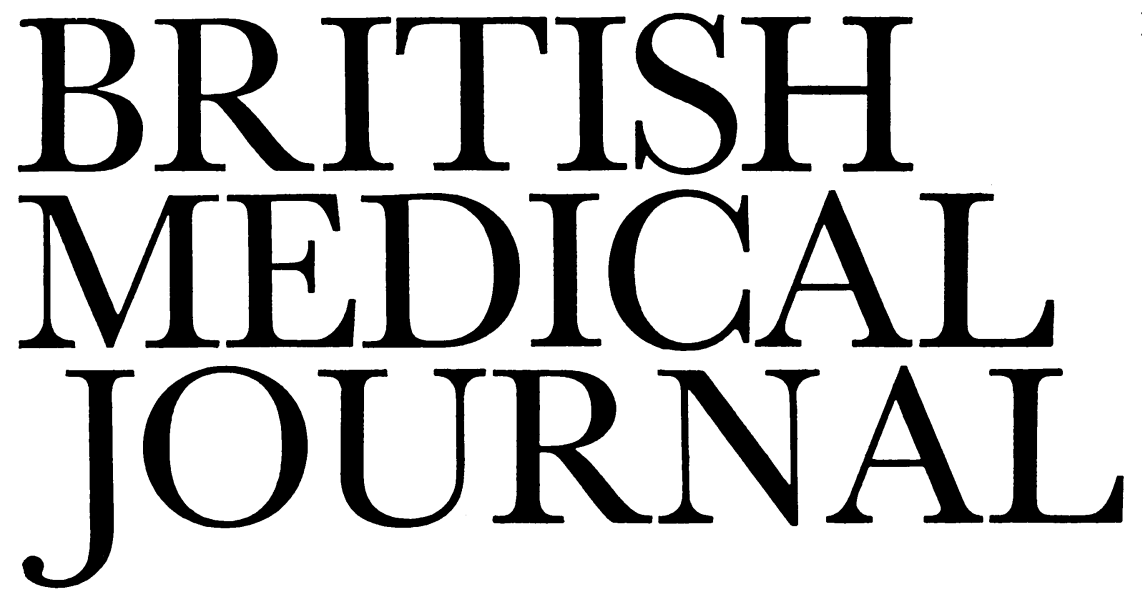

LONDON, SATURDAY 5 NOVEMBER 1983

\title{
Business management for the NHS?
}

If the effectiveness of the National Health Service was measured in column inches of reports about it Britain's health care would indeed be the envy of the world. Reality is different, and NHS staff will question whether so soon after a major restructuring, ${ }^{1}$ the Rayner scrutinies on efficiency, ${ }^{2}$ and the introduction of performance reviews ${ }^{3}$ yet more changes, this time proposed by Mr Roy Griffiths, managing director of a successful high street supermarket chain, will do more than unsettle a demoralised management. Mr Griffiths's study, ${ }^{4}$ summarised at $\mathrm{p} 1391$, was commissioned as a matter of urgency by a Secretary of State who is convinced that the health service is overadministered but ill managed. ${ }^{5}$ Despite the inauspicious circumstances and the short time in which he was given to complete his task Mr Griffiths has come out with some promising suggestions that should help to improve standards of management and thus of patient care.

Clearly the report gave Mr Norman Fowler, the Secretary of State for Social Services, the formula he had wanted, for on the day of publication he told parliament that he would set up the new structures proposed for the Department of Health and Social Security and (subject to consultation) hope to introduce the plans generally by April 1984 .

Two major problems have bedevilled the administration of the NHS: firstly, the long chain of responsibility stretching from parliament and the Secretary of State to the doctor and nurse at the patient's bedside, and, secondly, the tension between management and clinicians. ${ }^{6}$ The Royal Commission on the National Health Service recognised these problems, and dealt with the first by recommending removal of one tier of management-the area health authorities. ${ }^{7}$ It did not, however, propose any change in consensus management, the solution chosen in the 1972 reorganisation to resolve conflict between doctors' clinical freedom and the administration's responsibility to manage. ${ }^{8} \mathrm{Mr}$ Griffiths and his colleagues have tackled these problems head on. "We believe," they say in their letter to Mr Fowler, "that a small, strong general management body is necessary at the centre (and that is all that is necessary at the centre for the management of the NHS) to ensure that responsibility is pushed as far down the line as possible-that is, to the point where action can be taken effectively." Having pushed responsibility down the line they recommend "a general manager (regardless of discipline) at authority level," (their italics); argue that all day to day decisions should be taken "in the main hospitals and other units of management"; and urge that clinicians should be involved "more closely in the management process, consistent with clinical freedom for clinical practice." The authors also declare that clinicians must participate more fully in discussion about priorities in the use of resources (a point cogently argued in the $B M \mathcal{F}$ leading article last week). ${ }^{6}$ So critical to effective management at local level do they see the doctors' participation that they have already organised small scale studies in six hospitals, studies that they judge to have been successful. No details are, however, given-which is a pity, given the importance of effectively balancing the needs of clinical practice against those of management.

Mr Griffiths makes no apologies for proposing "business" solutions to the NHS's management difficulties. Indeed, he argues that the similarities between NHS management and business management are much more important than the differences-such as the absence of the profit motive and wider social responsibilities of the NHS-which he criticises as being "overstated." This judgment may be rather sanguine. The profitability of a commercial organisation does provide an observable if crude criterion of performance, something the NHS lacks, and the pressures resulting from the "wider social responsibilities" can, and often do, severely restrict the NHS management's ability to take administratively or financially sensible decisions. Even so, Mr Griffiths's clear arguments suggest that he has grasped the complexities of the NHS and his proposals deserve careful consideration.

The thrust of the proposals from this group of business experts is, not surprisingly perhaps, to convert the health service into a "corporation," albeit so constructed as to preclude the need for parliamentary legislation to launch it. At the top will be a health supervisory board-the board of directors-comprising the Secretary of State, the Minister for Health, the permanent secretary, the chief medical officer, the chairman of the NHS management board, and two or three non-executive members with business experience. A small, multiprofessional NHS management board would be responsible for the overall running of the NHS and would report 
to the supervisory board. The concept of a health service corporation is not new. ${ }^{9}$ Indeed, the royal commission considered the idea and rejected it but with a caveat that it was a matter "that ministers should keep under review." Perhaps its time has come. Certainly, the proposal, with the implication that the Department of Health and Social Security would be much reduced in size and influence, is one that will appeal to this government. It is also a proposal that will provoke hostility from some members of parliament, who will see it as diminishing their influence; from the Civil Service, who will be losing jobs; and from some health service unions, who may see it as reducing the opportunities for lobbying or for holding up changes that they oppose. If it improves management, concentrates more resources on patient care, reduces interference from the DHSS, and improves industrial relations (the authors want personnel management strengthened) doctors should welcome the concept.

One recommendation that will be contentious but which is crucial to improving the speed and quality of decision making is that a health authority's general manager "would be the final decision taker for decisions normally delegated to the consensus team, especially where decisions cross professional boundaries or cause disagreement and delay at present." This modification of consensus management has already provoked hostile responses from the Royal College of Nursing, ${ }^{10}$ but the BMA has been more welcoming. The secretary, Dr John Havard, said last week that clinicians had become increasingly frustrated with the delays that accompanied even relatively unimportant decisions in the NHS. The association will study closely the detailed arrangements proposed in the Griffiths report and-in line with the policy of the representative body in 1980-it will challenge the concept of a non-medical chief executive.

Doctors will welcome the call for less of their time to be spent in committees and the proposals point the way to achieving this. More of their time can then be spent with patients - which, when all is said and done about management, is what the NHS is about. Fortunately, Mr Griffiths has not forgotten them. "It is central to the approach of management," his letter states, "to ascertain how well the service is being delivered . . . by obtaining the experience and perceptions of patients and the community ... respond directly to this information ... act on it . . . and monitor performance against it. . . " Coming from a senior executive of one of the most successful consumer oriented businesses in Britain, this advice should be heeded. The opinions of patients and the community deserve as careful a hearing as that of health professionals and managers. If this is seen to happen it should strengthen the NHS's ability to cope rationally with the unfair demands of the pressure groups that flourish round the fringes of the NHS.

1 Anonymous. Reorganisation à la carte. [Editorial.] $\mathrm{Br} \mathrm{Med} \mathcal{F} 1982 ; 284$ 769-70.

${ }^{2}$ Anonymous. Sir Derek Rayner to advise on NHS performance. $\mathrm{Br} \mathrm{Med} \mathrm{f}$ $1982 ; 284: 1208$.

${ }^{3}$ Department of Health and Social Security. Health services management performance indicators. HN(83)25. London: DHSS, 1983.

4 NHS Management Inquiry. Report. London: DHSS, 1983. (Griffiths report.)

${ }^{5}$ Russell W. Political parties fight to champion NHS. Br Med $\mathcal{f} 1983$; 287:1233.

${ }^{6}$ Hampton JR. The end of clinical freedom. [Editorial.] Br Med $\mathcal{F} 1983$; 287:1237-8.

${ }^{7}$ Royal Commission on the National Health Service. Report. Cmnd 7615. London: HMSO, 1979:298-331.

${ }^{8}$ Department of Health and Social Security. Management arrangements for the reorganised National Health Service. London: HMSO, 1972.

${ }^{9} \mathrm{~W}$ iseman J. A health corporation ? Br Med f 1967;ii:102-3.

10 Anonymous. Mixed reaction to inquiry findings. The Times 1983 Oct $26: 5$.

\section{Searching the literature}

Peter P Morgan, scientific editor of the Canadian Medical Association fournal, recently suggested" that "a literature search should be regarded as a 'method' just like a treatment or diagnostic procedure and should be described in the methods section of most papers." His intention was not that readers wishing to validate the work described in the paper should be able also to test the search procedure but that the editor might be reassured that the author had reviewed the published work adequately when the references cited were few or old or all to the author's own publications.

Surely this is a subversive suggestion? Firstly, it subverts the principle, often subverted, that journal articles are for the readers, who are collectively perfectly capable of judging the adequacy of the references. Secondly, it subverts the task of the referees. Thirdly, it subverts the function of citing references-which is to acknowledge relevant previous work but emphatically not to show that the author has looked up everything ever published on the subject. And, fourthly, it is subversive in conveying the idea that, after the problem and all possible solutions had been comprehensively analysed, this is the definitive answer. In fact, a moment's thought discloses many flaws: for example, there is nothing to say what the search produced, that the author heeded the results, or that it was carried out properly.

An author is usually at least as worried about the adequacy of his review of published work as the editor because he is afraid that the editor or the referees will know of publications that he has failed to turn up, however diligent his search has been. What is he to do? How much time before, during, and after doing the work can he afford to spend on searching the literature?

In practice the author has two sources of published knowledge: his own background knowledge and reading, however he stores and retrieves it, and what he looks up specifically for the work in hand. Background knowledge naturally has limitations, because interests change and future needs are difficult to predict. Nevertheless, a faint memory-from a journal club meeting, for example-can sometimes produce a lateral reference that no search would throw up.

When making specific searches most of us have until recently looked only retrospectively. We start from a recent article, textbook, monograph, or conference proceedings and work through the references cited and the references cited by them. Having defined the medical subject headings that cover the subject, we can also work retrospectively through the Index Medicus. For a fee we may order computer searches of various data bases in consultation with the librarian. Now, however, that the Science Citation Index of the Institute for Scientific Information is more generally available we can also search prospectively. Each year the staff there insert details (including all the references) of 600000 articles into a data base that now contains more than 900 million articles. This material is available in book form as well as in computer format for locating all the publications in which the initial reference has been cited since it was published. The drawback to all these search systems is that they retrieve far too many publications; extracting the ones that are relevant to the particular needs of one's paper may be very time consuming.

I believe that most authors use these methods to review the previous work in their subjects, and that Dr Morgan is worrying too much. Clearly in the vast array of publications no one can expect to find, read, or assess every relevant one, and nuggets 